ISSN 1984-3372

http://portaldeperiodicos.unisul.br/index.php/EeN/index

\title{
UM ESTUDO DAS RELAÇÕES ENTRE A PAIXÃO DOS TORCEDORES E AS MARCAS PATROCINADORAS DE CLUBES DE FUTEBOL
}

\section{AN ASSESSMENT OF THE RELATIONSHIP BETWEEN FANS' PASSION AND SPONSORING BRANDS IN PROFESSIONAL SOCCER}

\section{UN ESTUDIO DE LAS RELACIONES ENTRE LA PASIÓN DE LOS PARTIDARIOS Y LAS MARCAS PATROCINADORAS DE CLUBES DE FÚTBOL}

\section{Renata Gonçalves Santos Silva}

Doutoranda em Administração pela Pontifícia Universidade Católica do Rio Grande do Sul, PUCRS, Brasil Endereço: Av. Ipiranga, 6681, CEP 90619-900, Partenon, Porto Alegre, RS - Brasil

Telefone: (51) 3320-3500

E-mail: renatagssilva@hotmail.com

\section{Edar da Silva Añaña}

Professor Adjunto da Universidade Federal de Pelotas e Pesquisador apoiado pelo CNPq Doutorado em Administração pela Universidade Federal do Rio Grande do Sul, Brasil Endereço: R. Gomes Carneiro, n. 1, Porto, CEP 96010-280, Pelotas, RS - Brasil Telefone: (53) 3921-1326

E-mail: edaranana@gmail.com

\section{Camila Elisa dos Santos Alves}

Mestranda em Administração pela Universidade Federal do Rio Grande do Sul, Brasil Endereço: Av. Bento Gonçalves, 9500, Agronomia, CEP 91501-970, Porto Alegre, RS - Brasil Telefone: (51) 3308-6000

E-mail: camilaelisaalves@hotmail.com

\section{Gustavo da Rosa Borges}

Doutorando em Ciências Contábeis e Administração pela Universidade Regional de Blumenau, FURB, Brasil Endereço: R. Antônio Da Veiga, Victor Konder, CEP 89012-500, Blumenau, SC - Brasil

Telefone: (47) 3221-6000

E-mail: adm.gustavo@ig.com.br

Artigo recebido em 20/03/2014. Revisado por pares em 13/07/2014. Reformulado em 05/09/2014. Recomendado para publicação em 08/12/2014 por Ademar Dutra (Editor Científico). Publicado em 30/12/2014. Avaliado pelo Sistema double blind review.
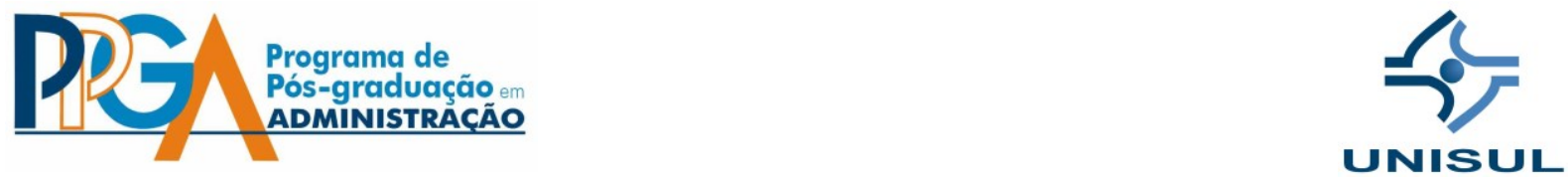

\section{(1)(9)}




\section{RESUMO}

O futebol é um esporte de grande destaque no Brasil e, por esta razão, o patrocínio de equipes vem despertando cada vez mais o interesse das empresas. Este estudo busca entender como a associação de uma marca a um clube de futebol é afetada pela condição momentânea do time, e se o próprio sentimento que o torcedor tem pelo clube influencia a imagem da marca anunciada. Ao todo são testadas cinco hipóteses, e o resultado sugere que a marca patrocinadora de um clube de futebol tem melhor avaliação quando associada à imagem do atleta símbolo, do que à equipe como um todo.

Palavras-chave: Marketing Esportivo; Patrocínio; Imagem da Marca.

\section{ABSTRACT}

Football is a national passion in Brazil, and for this reason, companies interest in sponsoring teams is increasing. This study seeks to understand how a sponsoring brand is affected by the momentary condition of a football team, and evaluate whether fans' attachment to the brand also influence the image of the advertised brand. Five hypotheses were tested and results suggest the brand sponsor a football club is best assessed when associated to a referenced athlete image, than to the team image as a whole.

Keywords: Sports Marketing; Sponsorship; Brand Image.

\section{RESUMEN}

El fútbol es un deporte de grande destaque en Brasil, y por esta razón, el patrocinio de equipos viene despertando cada vez más el interés de las empresas. Este estudio busca entender como la asociación de una marca a un club de fútbol es afectada por la condición momentánea del equipo, y se lo proprio sentimiento que el torcedor tiene por su club influencia el imagen de la marca anunciada. En su totalidad, son testadas cinco hipótesis y el resultado sugiere que la marca patrocinadora de un club de fútbol es más bien evaluada cuando es asociada con la imagen del atleta símbolo que con el equipo como un todo.

Palabras-clave: Marketing Deportivo; Patrocinio; Imagen de Marca. 


\section{INTRODUÇÃO}

No Brasil, o futebol é uma paixão nacional, sendo o esporte mais difundido do país, tanto pela população quanto pela mídia, que o expande de forma singular em relação a qualquer outra modalidade. O futebol é capaz de provocar sentimentos difíceis de serem explicados: é uma mistura de paixão, devoção, fanatismo, e outros tantos sentimentos exteriorizados de diferentes maneiras. A manifestação de lealdade ao time pode variar desde a simples ostentação das suas cores em peças de vestuário, até o extremo de tatuar o símbolo do clube na própria pele (OLIVER, 1999). De acordo com Branchi (2002), o esporte é uma mistura de razão e paixão, apta a gerar os mais diferentes comportamentos e condutas éticas e, justamente por esta razão, apaixona, atrai e emociona. Para o autor, o esporte é um catalisador de efeitos positivos para empresas que precisam comunicar-se de forma ágil com seus consumidores. Segundo Zunino (2006):

O volume de negócios gerados pelo esporte no Brasil, considerando o aumento da cobertura de mídia e investimentos na área, permite afirmar que essa temática necessita de um maior envolvimento por parte da academia na área da Administração, principalmente nas áreas de estratégias das empresas, marketing esportivo e comportamento do consumidor no que tange, principalmente, às relações sociais entre torcedores e empresas relacionadas ao produto esportivo. (ZUNINO, 2006, p.1).

A utilização dos clubes de futebol e de jogadores renomados como forma de divulgar uma marca tem sido uma estratégia cada vez mais adotada pelas empresas. O uso de endossante, também conhecido como porta-voz, ou "aquele que incorpora o discurso do anunciante, oferecendo o seu aval" (GOLDBERG; HARTWICK, 1990; STERNTHAL; PHILLIPS; DHOLAKIA, 1978 apud GIGLIO, 2004) difunde o patrocinador ultrapassando as barreiras geográficas, visto que o futebol brasileiro repercute internacionalmente. Como consequência, torna-se essencial avaliar o efeito que essa associação provoca na mente dos torcedores. Conforme Keller (2003), em uma economia cada vez mais conectada, é crucial entender os efeitos que a ligação da marca a outros elementos, como pessoas, lugares, coisas, ou mesmo com outra marca, provoca sobre o comportamento do consumidor.

Como forma de obter sucesso crescente, é notória a necessidade de gerenciar a imagem da marca. De acordo com Bauer, Sauer e Exler (2008), a imagem da marca pode ser 
descrita como o resultado de cumulativas associações que um consumidor faz, em sua mente, a respeito de um produto. Desta maneira, entende-se que o cliente cria um conceito acerca de determinada marca, de tal forma que esta conceituação o influencia no processo de decisão de compra. Assim, interessa avaliar se a associação de uma marca a um clube de futebol é afetada, ou não, pela condição momentânea do time em uma competição; ou seja, se a imagem do clube afeta a imagem da marca patrocinadora, e se o próprio sentimento do torcedor pelo clube influencia a imagem da marca anunciada. O presente estudo busca responder se, e em que medida, a paixão clubística é capaz de modelar a percepção dos torcedores quanto a uma marca endossada por um clube de futebol e seus jogadores.

Em relação ao patrocínio, Meenaghan (2001) e Schlesinger et al. (2012) já destacavam que este tipo de divulgação gera uma resposta emocional dos consumidores ou admiradores, sendo que esta resposta perceptiva contribui para a imagem das organizações envolvidas. Schlesinger et al. (2012) reforçam que o patrocínio tem crescido consideravelmente desde o início do século.

Este artigo tem o intuito de analisar como a paixão por um time de futebol influencia a forma como as pessoas percebem uma marca endossada pelo clube e por seus jogadores. Especificamente, busca: (I) analisar a influência da paixão dos torcedores na forma como estes avaliam seu clube do coração, os jogadores e a marca patrocinadora; (II) verificar como os torcedores de um clube de futebol percebem a marca patrocinadora de seu time; (III) investigar a influência da imagem do clube na percepção de sua principal marca patrocinadora; (IV) averiguar a influência da imagem do atleta símbolo na percepção da marca endossada por ele; (V) verificar como os torcedores de um clube de futebol percebem uma marca endossada pelo atleta símbolo de seu time.

Grohs e Reisinger (2014) reforçam que o entendimento de como funciona o patrocínio de eventos esportivos é fundamental para o desenvolvimento de estratégias eficazes para o seu efeito.

\section{REVISÃO DA LITERATURA}




\subsection{MARKETING ESPORTIVO}

O marketing esportivo, antes utilizado principalmente por empresas de cigarro, cerveja e automóveis, segundo Keller e Machado (2006), passou a ser uma estratégia adotada por vários tipos de empresas e, nos últimos anos, cresceu rapidamente, alcançando 25 bilhões de dólares, em uma perspectiva global. Ainda para estes autores, o patrocínio de eventos proporciona um canal de comunicação diferente com os consumidores, pois faz parte de momentos especiais e pessoalmente importantes na vida dos clientes. Desta forma, patrocinar eventos promove uma aproximação entre empresa e público-alvo.

Melo Neto (2007) afirma que as organizações investidoras do esporte apresentam características essenciais, isto é, possuem marcas fortes ou potencialmente fortes e nele buscam novas formas de comunicação com os seus públicos e com os mercados onde atuam. O autor afirma, ainda, estas organizações utilizarem o esporte como uma mídia alternativa, objetivando, principalmente, o reforço e a disseminação da marca e a melhoria da imagem corporativa. Ao mesmo tempo, buscam uma comunicação mais eficiente com seus segmentos de clientes atuais e futuros.

O comportamento do consumidor de esportes é visto como um processo que envolve escolhas, aquisições e uso de produtos ou serviços relacionados ao esporte com intuito de satisfazer as necessidades e oferecer benefícios (FUNK, 2008).

Apesar do crescente interesse pelo marketing esportivo, ainda existem dúvidas sobre os benefícios de patrocinar um clube de futebol. Um argumento comum é que os torcedores de um clube podem deixar de comprar os produtos/serviços da empresa patrocinadora do clube rival. Por esta razão, empresas concorrentes optam por patrocinar clubes oponentes como forma de conquistar os torcedores de uma ou de outra equipe como consumidores. Ainda há organizações que patrocinam clubes rivais simultaneamente, de maneira a evitar qualquer possibilidade de perda de clientes - pelo menos daqueles mais fanáticos, que não suportariam adquirir produtos/serviços de uma empresa patrocinadora da equipe rival (FERRARI; SILVEIRA, 2009). 
Percebe-se que o marketing esportivo representa uma forma de comunicação de custo relativamente baixo (MELO NETO, 2007) e grande eficácia, utilizada por empresas com o intuito de se destacarem no cenário nacional e, até mesmo, internacional.

\subsection{PATROCÍNIO: CANAL DE COMUNICAÇÃO}

Conforme Kotler e Keller (2006), as ferramentas de comunicação compreendem: a propaganda, a promoção de vendas, as atividades de relações públicas/publicidade, a venda pessoal, o marketing direto e os eventos e experiências. Esta última ferramenta tem ocupado um espaço significativo nas estratégias de promoção de marketing das empresas. Ela compreende um conjunto de ações de comunicação cujo intuito é tornar a empresa parte de momentos especiais e relevantes na vida pessoal de seus públicos, estreitando o relacionamento da organização com seu ambiente. Para estes autores, a principal atividade que compõe a ferramenta eventos e experiência é o patrocínio, nas mais variadas modalidades: esportes, festivais, artes, causas, passeios e atividades de rua.

De acordo com Mattar (2007), das diversas modalidades de patrocínio, o esporte é a que recebe o maior volume de ações e os maiores volumes de investimentos. No Brasil, a preferência pela modalidade esportiva, principalmente pelo futebol, justifica-se pela enorme ligação com o esporte, considerado paixão nacional (AFIF, 2000 apud FERRARI; SILVEIRA, 2009). O crescente interesse no patrocínio como forma de anunciar produtos intensificou-se a partir da década de 70 , com a proibição de veicular propagandas alusivas à indústria tabagista e alcoólica (BUDOLLA; SOUZA, 2005). Aliado a isto, Crompton (1994 apud BUDOLLA; EMMERICK; FREGA; SANTOS, 2006) aponta outros fatores que impulsionaram o crescimento do patrocínio, principalmente esportivo, por empresas de diferentes ramos: aumento do custo da mídia televisiva, perda da eficiência dos anúncios em mídias tradicionais, diversificação dos veículos de comunicação, crescimento da comercialização do esporte e acirramento da competitividade. Diante desses fatores, torna-se evidente a necessidade de encontrar canais de divulgação diferenciados.

Segundo Keller e Machado (2006), há uma série de razões para o patrocínio de eventos: identificar um público-alvo ou estilo de vida específico; majorar a lembrança da marca; criar ou reforçar as percepções do consumidor das associações-chaves de imagem da 
marca; promover dimensões da imagem da empresa, criar experiências e provocar sentimentos; demonstrar comprometimento com a sociedade e com causas sociais e, ainda, entreter clientes importantes ou recompensar seus colaboradores (áreas especiais em eventos). Para Melo Neto (2007), o patrocínio caracteriza-se por ser uma mídia alternativa e a visibilidade proporcionada pelo esporte permite às organizações terem poder de penetração imenso em milhares de espectadores, telespectadores, leitores e praticantes em todo o mundo (HAIACHI; MATARUNA, 2008).

Schlesinger et al. (2012) destacam que o patrocínio esportivo tem crescido consideravelmente desde o início do século. Grohs e Reisinger (2014) descrevem que a busca por novos patrocínios é uma parte significativa do marketing, especialmente em eventos esportivos.

Oliveira (2010) reforça que as organizações não governamentais precisam saber utilizar a mídia para se comunicar com a comunidade. Este efeito pode influenciar tanto as empresas patrocinadoras, quanto os clubes de futebol. Portanto, a estratégia de patrocínio deve ser bem planejada, conforme destacado por Oliveira (2010).

\subsubsection{Patrocínio de Atletas - Endosso}

O patrocínio de atletas/endosso é um tipo de patrocínio esportivo muito explorado pelas empresas. O termo endosso é comumente empregado para descrever a cooptação entre uma organização/marca/produto e uma celebridade. Na prática, nada mais é que o patrocínio de um atleta, pois inclui auxílio (financeiro ou material) em troca da associação de imagem do esportista, caracterizando-o como garoto propaganda (ESCOBAR, 2002).

Pessoas famosas e admiradas pelos consumidores endossam produtos desde o século XIX (ERDOGAN, 1999). O uso de celebridades para promover produtos é utilizado com o intuito de atrair a atenção para uma marca e modelar as percepções sobre ela, em razão das inferências que os consumidores fazem com base nas informações a respeito da personalidade famosa que a representa (KELLER; MACHADO, 2006). Por esta razão, é fundamental a escolha do endossante levar em conta a reputação dele e sua imagem perante a sociedade. Escobar (2002) descreve o patrocínio de atletas como uma estratégia 
de comunicação bastante utilizada, na qual se aproveita o carisma de uma celebridade para distinguir a imagem da marca oferecida.

O uso de celebridades como endossantes aumentou significativamente nos últimos anos. Elas têm sido utilizadas para promover diversos artefatos, desde bebidas esportivas até telefones móveis, e o uso desse meio de comunicação parece interminável. Neste sentido, o uso de famosos não está limitado a nenhum segmento em particular, este tipo de endosso cruza todos os segmentos industriais (MISHRA; DHAR; RAOTIWALA, 2001).

Para Mishra et al. (2001), entre os principais fatores considerados pelas organizações na seleção de um endossante estão a credibilidade e a simpatia da personalidade, pois tem sido relatado ser menos eficaz uma celebridade que endossa mais de um produto. Ohanian (1990) agrega, ainda, o conceito de atratividade do endossante como uma dimensão a ser considerada na escolha de uma personalidade. Para este autor, as mais atraentes são também consideradas as mais benquistas, e têm um impacto positivo na avaliação dos produtos. Keller e Machado (2006) corroboram a posição de Mishra et al. (2001), quando declaram que o uso de uma celebridade no endosso de vários produtos pode resultar em falta de qualquer significado específico de produto. Ao mesmo tempo, pode haver reflexo em sua reputação, sendo elas consideradas oportunistas. Keller e Machado (2006) relatam, ainda, que os consumidores, muitas vezes, creem que o endossante não acredita na marca representada ou nem mesmo a usa.

Parmentier e Fischer (2012) esclarecem que jogadores de clubes de futebol são vistos como marcas. Assim sendo, profissionais de marketing investem grandes montantes financeiros para ter celebridades como promotoras de seus produtos, com o pressuposto de o público reagir positivamente à associação dos famosos com o seu produto (SCOTT, 1991). No caso do futebol, um atleta vitorioso, bem sucedido, é um excelente produto para as empresas. O seu talento, vastamente reconhecido por todos, é percebido pelo consumidor como de alta qualidade, excelente performance e garantia de sucesso. Tais características do desportista são denominadas a imagem do atleta, portanto, é importante para ele preservar sua imagem. Atitudes, dentro ou fora de campo, que a comprometam, o estigmatizarão 
como um jogador-problema. Isto o desclassifica como um bom produto para as empresas (MELO NETO, 2007).

Parmentier e Fischer (2012) esclarecem que o desempenho do jogador influencia diretamente na sua imagem. Arai, Ko e Ross (2014) alertam que o atleta é uma imagem que depende além do seu desempenho, de sua aparência e do seu estilo de vida.

\subsubsection{Patrocínio de Eventos e Equipes}

Para Escobar (2002), o patrocínio de eventos e de equipes diz respeito à associação entre uma marca/produto e a atividade esportiva e seus organizadores - equipes/entidades reguladoras.

No Brasil, o patrocínio de equipes é fato recente, já que essa prática teve início nos anos 80 , quando os clubes começaram a divulgar o nome de empresas em suas camisas. Até aquele momento o patrocínio ainda encontrava muita resistência por parte das agremiações e dos torcedores. $O$ vôlei teve papel importante nesse aspecto, pois foi o esporte que saiu na frente na área (AFIF, 2000 apud FERRARI; SILVEIRA, 2009).

Melo Neto (2007) relata que, ao associar-se a uma equipe, o patrocinador procura vincular sua marca ao desempenho dela, com foco na utilização da sua força promocional. Segundo o autor, o patrocínio de clubes, no Brasil, costuma voltar-se para esportes consagrados e clubes de destaque nacional, devido à cobertura massiva da mídia e o interesse do público.

De acordo com Keller e Machado (2006), a associação de uma empresa a outras marcas ou entidades com o intuito de promover sua marca, forma uma parceria denominada co-branding. O co-branding "ocorre quando duas ou mais marcas existentes são combinadas ou promovidas em conjunto de um modo qualquer". Ao fazer uma conexão entre a marca de uma e a de outra entidade, os consumidores podem formar uma associação mental da marca com a entidade e, consequentemente, quaisquer outros julgamentos e sentimentos ligados a essa entidade (KELLER; MACHADO, p. 195, 2006).

Gaspar et al. (2014) descrevem que a associação de organizações geralmente ocorre por haver objetivos mútuos e, muitas vezes, o marketing influencia o resultado destas relações. Esta associação proposta pode contribuir para uma melhor visibilidade das 
organizações no mercado. Para tanto, é importante haver um compartilhamento de conhecimento. Carvalho e Veras (2010) apontam para um compartilhamento de conhecimento mais eficaz se houver a formalização das ações; isto pode denotar em um maior conhecimento.

Grohs e Reisinger (2014) alertam que o envolvimento na atividade patrocinada melhora a imagem do patrocinador, reforçando uma relação entre os envolvidos. Portanto, verifica-se que o modo de patrocínio é uma decisão estratégica, tanto para as empresas quanto para os clubes, e o sucesso depende de ambos.

\subsection{PERSONALIDADE DA MARCA}

A personalidade da marca, desde o início do século, vem motivado consideravelmente profissionais do marketing a melhor explorá-la (MOZOTA, 2003). Ela é definida por Aaker (1997, p. 347) como um "conjunto de características humanas associadas a uma marca". O uso simbólico de características humanas designadas a marcas é justificado pelo fato de os consumidores frequentemente tratarem as marcas com traços da personalidade humana (GILMORE, 1919 apud AAKER, 1997). Rook (1985 apud AAKER, 1997) certifica que os consumidores facilmente pensam nas marcas como se estas fossem celebridades ou figuras historicamente famosas. Ainda, elas podem ser singularizadas como femininas ou masculinas, modernas ou clássicas, da mesma forma como as pessoas são individualizadas (MUNIZ, 2005).

Para Ekinci e Hosany (2006), a personalidade da marca tem origem no simbolismo. Alega-se que os consumidores consideram seus produtos preferidos como uma extensão de si mesmos e, portanto, seu comportamento de compra é motivado pelo valor simbólico do produto (MOWEN, 1990 apud EKINCl; HOSANY, 2006).

Aaker (1997), em seu estudo sobre as dimensões da personalidade da marca, desenvolveu uma escala - Brand Personality Scale (BPS) - na qual são identificadas cinco dimensões distintas de personalidade: sinceridade, excitação, competência, sofisticação e robustez. A construção dessa escala permite a gerentes e pesquisadores compreenderem melhor as percepções e as atitudes dos consumidores com relação às marcas (AAKER, 1998 
apud MUNIZ, 2005), já que, de acordo com a personalidade percebida pelos consumidores, estes determinam se aquela marca é ou não apropriada para ele (MUNIZ, 2005).

A personalidade de marca torna-se cada vez mais importante porque o produto ou serviço, por si só, não possui representatividade emocional suficiente para impulsionar respostas emocionais dos clientes (MOZOTA, 2003). Sua característica emocional é tão convincente que é capaz de influenciar a lealdade do cliente (MOZOTA, 2003; DAS, 2014).

\section{HIPÓTESES DE PESQUISA}

O futebol proporciona grande prazer ao seu público e, ao mesmo tempo, provoca enorme excitação advinda dos momentos de tensão na expectativa do gol. Este esporte permite, aos torcedores, a possibilidade de vivência controlada de seus descontroles; isto é, a expressão de emoções que não podem ser anunciadas em outras atividades, a não ser no espetáculo esportivo (REIS, 2010).

Ainda que a escolha não seja baseada exclusivamente em critérios racionais, a adoção de um time do coração pressupõe que o torcedor espere alguma recompensa funcional ou psicológica - dessa relação. Mesmo a escolha do time resultando da influência de outras pessoas (pais ou amigos, por exemplo), e não esteja necessariamente ligada ao desempenho do clube em competições recentes, ainda assim o torcedor sempre esperará algum tipo de recompensa, seja pela expectativa de grandes conquistas futuras, seja pela melhor aceitação no seu grupo de referência (HOYE et al., 2006 ; GIGLIO, 2010).

Ao eleger um time para chamar de seu, o torcedor devota a este a sua lealdade (já que implicitamente renuncia à possibilidade de torcer ou de dar suporte financeiro a times adversários), mas, em troca, espera ser recompensado pelo recebimento de benefícios tangíveis (desconto nos ingressos, utilização de academias ou piscinas, etc.), de benefícios psicológicos (comemorar as conquistas do seu time, ironizar sobre o desempenho dos adversários, etc.), ou de benefícios sociais (melhor aceitação no grupo com o qual se relaciona).

Meenaghan (2001) esclareceu que o patrocinador gera uma resposta emocional no consumidor/admirador, e quanto mais fanático ele for, maior afinidade terá com o 
patrocinador. Analisando os pressupostos teóricos aqui enfatizados, é possível esperar o seguinte:

H1a: quanto maior a paixão pelo clube, melhor a imagem do clube aos olhos do torcedor, nos bons momentos vividos pelo time, ou quando as circunstâncias favorecem a satisfação deste último;

H1b: quanto maior a paixão pelo clube, pior a imagem do clube aos olhos do torcedor, nos maus momentos vividos pelo time, ou quando as circunstâncias dificultam a satisfação deste último;

H2a: quanto maior a paixão pelo clube, melhor será a imagem do atleta símbolo durante as boas fases do time, ou quando as circunstâncias favorecem a satisfação do torcedor;

H2b: quanto maior a paixão pelo clube, pior será a imagem do atleta símbolo durante as más fases do time, ou quando as circunstâncias dificultam a satisfação do torcedor.

A dedicação dos atletas para com o clube, em especial aquela demonstrada pelo atleta símbolo, sugerem acerto por parte da Administração ao contratar jogadores. Como os torcedores são clientes passionais (CÁRDIA, 2004 apud MAYER, 2010), é natural esperarem sempre mais dos seus jogadores e dirigentes do que aquilo que estes conseguem dar em condições normais. Atletas participantes de grandes feitos ou demonstrando excepcional denodo ao time, quase sempre caem nas graças da torcida; porém, aqueles que não se mostram suficientemente comprometidos ou disciplinados, ou que não sejam capazes de suar sangue nos momentos decisivos, correm o risco de serem vaiados em campo, ou mesmo de serem rejeitados pela torcida. Logo, é possível esperar a sequência:

H3: quanto melhor for a imagem do atleta símbolo, melhor será a imagem do clube.

O marketing esportivo é o meio pelo qual as empresas buscam distinguir-se através da identificação com heróis desportistas e suas habilidades; isto ocorre devido à intensa afeição emocional por equipes e atletas (SCHLOSSBERG, 1996 apud LEOCÁDIO et al., 2007). Ao estampar a sua marca na camisa de uma equipe, a empresa vincula sua imagem à performance do time, beneficiando-se, assim, da credibilidade dos atletas. Para Afif (2000 
apud LEOCÁDIO et al., 2007, p. 3) "com o bom desempenho do time ou dos atletas, as pessoas que até então se mostravam impassíveis quanto à marca que as patrocina, passam a construir uma imagem positiva da empresa. Entretanto, quando um jogador apresenta um comportamento inadequado, o patrocinador poderá ter sua imagem afetada, mesmo que indiretamente". Parmentier e Fischer (2012) reforçam que o desempenho do jogador influencia diretamente na sua imagem. Deste modo, espera-se:

\section{H4: quanto melhor a imagem do clube, melhor a imagem da marca patrocinadora;}

H5: quanto melhor a imagem do atleta símbolo, melhor a imagem da marca endossada por ele.

A figura 1 sintetiza as hipóteses de pesquisa deste estudo.

Figura 1 - Resumo das hipóteses de pesquisa

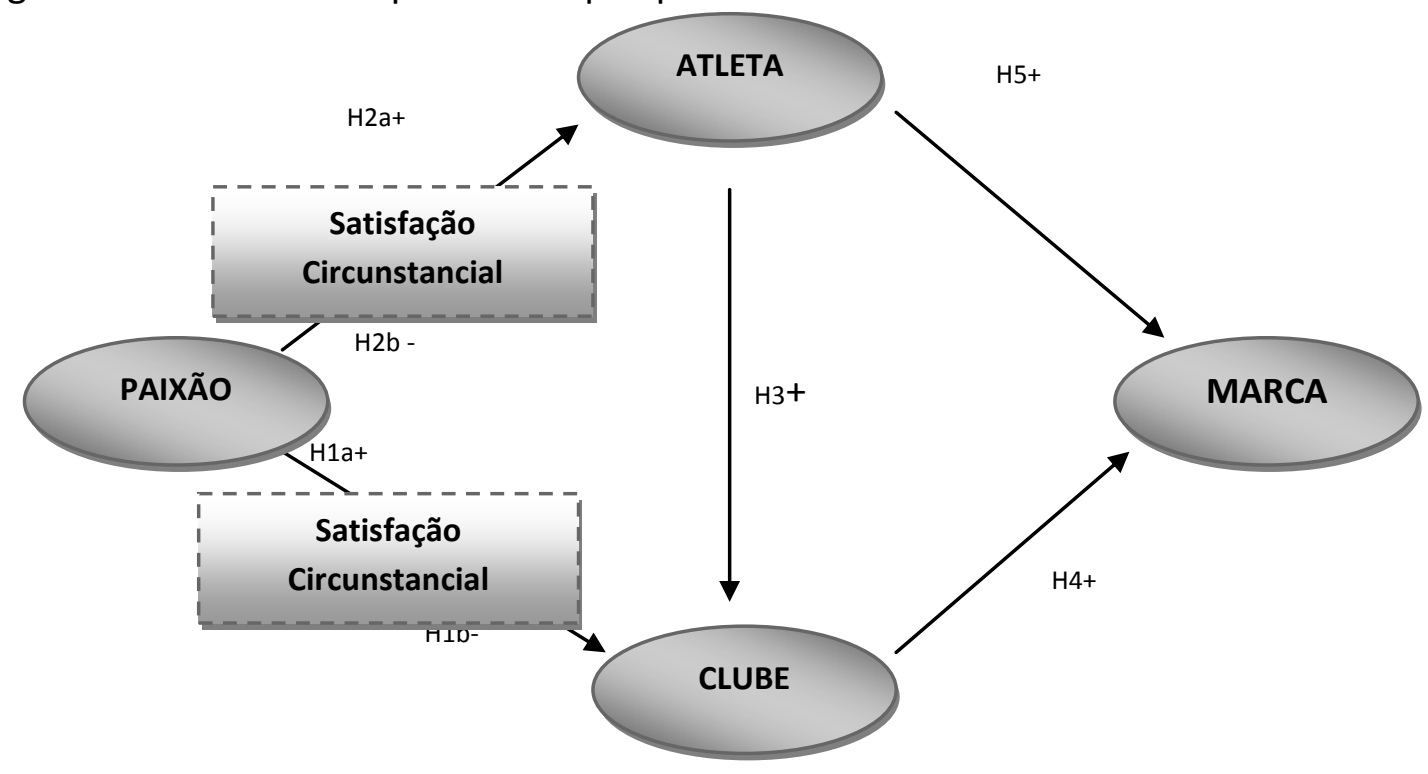

Fonte: elaborado pelos autores, 2014.

\section{METODOLOGIA}

O estudo caracteriza-se como pesquisa descritiva, de abordagem quantitativa e emprega o método survey em corte transversal único, isto é, a coleta de informações de uma amostra de entrevistados ocorre em um momento único (MALHOTRA, 2001). 
A pesquisa utiliza uma amostra de conveniência, uma técnica na qual, segundo Zikmund (2006), a amostragem aborda pessoas ou unidades que estão mais convenientemente disponíveis. Para a amostra, foram buscados torcedores do Grêmio FootBall Porto-Alegrense e do Sport Clube Internacional, clubes da primeira divisão do Campeonato Brasileiro, de grande destaque no meio futebolístico nacional e até internacional, assim como torcedores do Esporte Clube Pelotas e do Grêmio Esportivo Brasil, clubes representativos do futebol do interior do Rio Grande do Sul.

O interesse por levantar a opinião de torcedores de clubes do interior e da capital justifica-se pela necessidade de contrastar duas diferentes realidades bastante distintas: a realidade dos grandes clubes da capital, que geralmente conseguem manter renda de bilheteria durante o ano todo; e a realidade dos clubes do interior, cuja atividade, muitas vezes, é sazonal (formam times para disputar o campeonato regional e são obrigados a dispensar parte dos jogadores após). Além dos clubes supracitados, outros times também foram apontados pelos respondentes; entretanto, devido ao baixo número (6), este grupo foi desconsiderado nas análises.

Buscando responder à questão principal deste trabalho, foi construído um questionário composto de perguntas demográficas e de preferência futebolística, além de quatro construtos: Paixão Clubística, Imagem do Clube, Imagem do Atleta Símbolo e Imagem da Marca Patrocinadora. Para explorar a paixão do torcedor por seu clube de futebol, foi utilizada a escala do self estendido, de Sivadas e Venkatesh (1995), adaptada de Souza, Henrique e Brei (2006). O self é um construto utilizado para verificar o vínculo emocional que os indivíduos estabelecem com suas posses. De acordo com o que assegura Belk (1988, p. 153) "assim como a roupa, o jeito de falar e as joias distinguem uma pessoa das demais e marcam o seu jeito de ser, estas também servem para expressar a identidade do grupo e o sentido pertencimento das pessoas [ao grupo]". A imagem do clube foi avaliada através da escala de Beccarini e Ferrand (2006), traduzida, no Brasil, por Borges e Añaña (2010). Para o construto marca, fez-se uso de uma dimensão da escala de personalidade da marca de Aaker (1997). A imagem do atleta símbolo foi avaliada por quatro questões do tipo diferencial semântico de sete pontos, especialmente concebidas para este fim, cuja estrutura mostrouse confiável durante as análises, conforme será visto adiante. 
Os questionários foram aplicados impressos, e sua aplicação foi precedida de um teste de compreensão com seis indivíduos, no intuito de saber se o questionário atendia ao objetivo do trabalho, bem como para verificar a sua clareza. Durante este teste, observou-se a necessidade de realizar uma pequena modificação em uma das questões, na qual foi adicionada uma alternativa de resposta.

Foram coletados 189 questionários, dos quais 13 foram descartados por problemas no preenchimento. Deste modo, para fins de análise, utilizaram-se 176 questionários. A coleta de dados ocorreu entre os dias 14 e 23 de outubro de 2011.

A análise dos dados foi feita em duas etapas. Na primeira, os dados foram submetidos à Análise Fatorial Exploratória para avaliar a estrutura da escala de Imagem do Atleta, criada especialmente para esta finalidade e para identificar eventuais discrepâncias entre as dimensões das demais escalas empregadas e aquelas existentes nos dados. $\mathrm{Na}$ segunda etapa foi realizada a Análise Fatorial Confirmatória para analisar as relações entre os construtos e testar as hipóteses de pesquisa.

\section{RESULTADOS E DISCUSSÃO}

A respeito do perfil da amostra deste estudo, formada por torcedores de clubes de futebol, a maioria dos respondentes era do sexo masculino (60\%), fato já esperado, pois se trata de um tema preponderantemente masculino, apesar de o público feminino estar cada vez mais envolvido com esse esporte (FERRARI; SILVEIRA, 2009). A maior parte dos respondentes possui Ensino Superior (49,4\%) e reside na cidade de Pelotas/RS (92,6\%). Ainda com relação ao perfil dos torcedores, é possível constatar ser um grupo que procura manter-se informado, pois $59,1 \%$ dos entrevistados têm o hábito de ler jornal diariamente. Percebe-se, dentre os clubes do interior, o Grêmio Esportivo Brasil apresentar maior percentual de torcedores (28,98\%), enquanto o rival apresentou $18,75 \%$; com relação aos times da capital, o Grêmio Foot-Ball Porto Alegrense superou o rival Sport Clube Internacional $(22,16 \%)$, assumindo proporção maior de torcedores dentro da amostra $(26,14 \%)$. 


\subsection{ANÁLISE EXPLORATÓRIA}

Em um primeiro momento, os dados foram submetidos a uma análise fatorial exploratória com o intuito de verificar as correlações existentes entre as variáveis, de modo a agrupá-las em dimensões comuns. Para avaliar o grau de consistência interna das escalas, tomou-se como base o Alfa de Cronbach, cujo limite inferior aceito é 0,70 (para trabalhos confirmatórios), podendo atingir 0,60 em pesquisa exploratória (HAIR JR et al., 2005).

A paixão pelo time, aqui tratada como paixão clubística, foi avaliada através de seis variáveis adaptadas de Souza, Henrique e Brei (2006), os quais traduziram e validaram o trabalho de Sivadas e Venkatesh (1995) no Brasil. O resultado indicou que aquele instrumento presta-se satisfatoriamente para medir o construto, pois apresenta altas cargas fatoriais e confiabilidade aceitável (Alfa de Cronbach =0,922).

Durante a análise fatorial do construto imagem do clube foi possível identificar dois fatores, um composto por seis variáveis e outro por três. A escala original era formada por 10 itens; contudo, durante a análise, uma variável (Meu clube é, geralmente, bem administrado) teve de ser excluída, por apresentar carga cruzada nos dois fatores. Os fatores utilizados para determinar a imagem do clube foram denominados: imagem positiva do clube, porque sustenta variáveis que contemplam características favoráveis ao clube (Meu time é um grande clube de futebol; Meu clube ambiciona grandes conquistas; Meu clube tem um bom Centro de Treinamento; Meu clube tem um bom time; Meu clube tem um time guerreiro; Meu clube não tem sido afetado por escândalos); e imagem crítica do clube, pois, ao contrário do primeiro fator, apoia-se em variáveis que denigrem o clube (Os jogadores do meu time demonstram falta de garra; O meu time poderia ter melhores resultados; A gestão do meu clube deixa a desejar). O primeiro fator apresentou confiabilidade aceitável (Alfa de Cronbach = 0,808); porém, o Alfa de Cronbach do fator Imagem Crítica apresentou baixa confiabilidade $(0,541)$; no entanto, não foi excluído imediatamente para que pudesse ser avaliado melhor na fase confirmatória.

A escala utilizada para verificar a imagem do atleta símbolo foi estruturada pelos autores em cinco variáveis do tipo diferencial semântico de sete pontos, que avaliavam o atleta quanto: (1) à qualidade técnica, em uma escala em que o jogador poderia ser 
classificado entre os extremos de um perna de pau até um craque; (2) à dedicação, variável que considerava o atleta desde um mercenário até um guerreiro capaz de 'suar sangue pelo time'; (3) ao caráter, considerando um jogador desde um mau caráter até um exemplo de profissional; (4) à liderança, variável que julga o atleta entre os extremos de apenas mais um em campo até um líder em campo; e (5) ao reconhecimento, classificando o atleta desde uma pessoa muito discreta até uma celebridade. A partir da análise fatorial, verificou-se que se trata de um construto monofatorial, composto por quatro das cinco variáveis idealizadas. A variável reconhecimento não apresentou carga suficiente para compor o fator e, por isso, teve de ser excluída, visto não ser possível formar um novo fator com uma única variável (HAIR et al., 2005). A confiabilidade desta escala também mostrou-se aceitável (Alfa de Cronbach $=0,856)$. O fator Imagem do Atleta foi nomeado, desta forma, justamente por caracterizar este indivíduo.

Para avaliar a percepção dos torcedores acerca da marca patrocinadora de seu clube, adotaram-se nove variáveis pertencentes à dimensão sinceridade da escala de personalidade da marca de Aaker (1997); entretanto, nem todas se ajustaram e, portanto, algumas foram excluídas. Portanto, a escala original composta pelas variáveis: sólida, orientada para a família, interiorana, honesta, sincera, realista, original, sentimental e amigável foi reestruturada e os itens mantidos foram agrupados em um único fator, composto por: sincera, honesta, realista, amigável, original e sentimental. Assim como as escalas anteriores, esta também apresentou confiabilidade aceitável (Alfa de Cronbach $=$ $0,865)$.

Para identificar o momento vivido pelos clubes de futebol, foram inseridas no questionário questões acerca do desempenho dos clubes, bem como a respeito da eficiência da administração e da qualidade do elenco de jogadores. Assim, é possível analisar como os torcedores julgam o momento atual vivido pelo seu time. Com base na análise fatorial, identificou-se o construto Satisfação Circunstancial, composto por três variáveis e um único fator: desempenho nos últimos anos, qualidade do elenco e administração do clube (Alfa de Cronbach $=0,848)$.

A Tabela 1 mostra as cargas fatoriais e a confiabilidade de todos os construtos. 
Tabela 1 - Análise exploratória dos construtos

\begin{tabular}{|c|c|c|}
\hline Variáveis & Cargas Fatoriais & $\begin{array}{l}\text { Cargas } \\
\text { Fatoriais }\end{array}$ \\
\hline Paixão Clubística & Fator 1 & - \\
\hline $\begin{array}{l}\text { Eu formo parte da minha identidade a partir das cores e dos símbolos do } \\
\text { meu time. }\end{array}$ & 0,922 & - \\
\hline O meu time é parte do que eu sou. & 0,917 & - \\
\hline $\begin{array}{l}\text { Ser reconhecido como colorado/gremista/áureo } \\
\text { cerúleo/xavante/farrapo/etc. é fundamental para a formação da minha } \\
\text { identidade. }\end{array}$ & 0,908 & - \\
\hline O meu time (e os seus símbolos) ajudam a formar a minha identidade. & 0,839 & - \\
\hline Após as derrotas do meu time, eu sinto como se a derrota fosse minha. & 0,76 & - \\
\hline $\begin{array}{l}\text { Usar as cores do meu time ajuda-me a diminuir a distância entre o que } \\
\text { eu sou e o que eu tento ser. }\end{array}$ & 0,756 & - \\
\hline Alfa de Cronbach & 0,922 & - \\
\hline Imagem do Atleta & Fator 1 & - \\
\hline Dedicação & 0,879 & - \\
\hline Caráter & 0,87 & - \\
\hline Liderança & 0,823 & - \\
\hline Qualidade Técnica & 0,775 & - \\
\hline Alfa de Cronbach & 0,856 & - \\
\hline Personalidade da Marca Patrocinadora & Fator 1 & - \\
\hline [Marca] Sincera & 0,895 & - \\
\hline [Marca] Honesta & 0,855 & - \\
\hline [Marca] Realista & 0,854 & - \\
\hline [Marca] Amigável & 0,763 & - \\
\hline [Marca] Original & 0,737 & - \\
\hline [Marca] Sentimental & 0,563 & - \\
\hline Alfa de Cronbach & 0,865 & - \\
\hline Satisfação & Fator 1 & - \\
\hline Qualidade do elenco & 0,898 & - \\
\hline Desempenho nos últimos anos & 0,886 & - \\
\hline Administração & 0,848 & - \\
\hline Alfa de Cronbach & 0,848 & - \\
\hline Imagem do Clube & Imagem Positiva & $\begin{array}{l}\text { Imagem } \\
\text { Crítica }\end{array}$ \\
\hline Meu time é um grande clube de futebol. & 0,791 & - \\
\hline Meu clube ambiciona grandes conquistas. & 0,758 & - \\
\hline Meu clube tem um bom Centro de Treinamento. & 0,723 & - \\
\hline Meu clube tem um bom time. & 0,701 & - \\
\hline Meu clube tem um time guerreiro. & 0,661 & - \\
\hline Meu clube não tem sido afetado por escândalos. & 0,535 & - \\
\hline Os jogadores do meu time demonstram falta de garra. & - & 0,735 \\
\hline
\end{tabular}




\begin{tabular}{|l|c|c|}
\hline O meu time poderia ter melhores resultados. & - & 0,682 \\
\hline A gestão do meu clube deixa a desejar. & - & 0,657 \\
\hline Alfa de Cronbach & 0,808 & 0,541 \\
\hline
\end{tabular}

Fonte: Dados da pesquisa.

\subsection{ANÁLISE CONFIRMATÓRIA E DE VERIFICAÇÃO DAS HIPÓTESES DE PESQUISA}

Com o intuito de responder a questão principal deste estudo, bem como as questões secundárias, cinco hipóteses formam formuladas e testadas através de Análise Fatorial Confirmatória. A análise confirmatória representa o uso de uma técnica multivariada com o intuito de testar uma relação pré-especificada (HAIR et al., 2005). A figura 2 expõe as relações hipotetizadas e testadas, as quais serão descritas a seguir. Por conveniência, todas as relações testadas foram mantidas na mesma figura: as relações significativas com as respectivas cargas padronizadas, representadas por linhas sólidas, e as relações não confirmadas por linhas pontilhadas. O modelo foi construído e testado no software AMOS ${ }^{\mathrm{TM}}$ 18; o ajustamento foi considerado satisfatório conforme a literatura: $\mathrm{NFI}=0,813 ; \mathrm{TLI}=0,889$; $\mathrm{CFI}=0,907 ; \mathrm{RMSEA}=0,067$.

Figura 2 - Relações testadas, com as respectivas cargas padronizadas

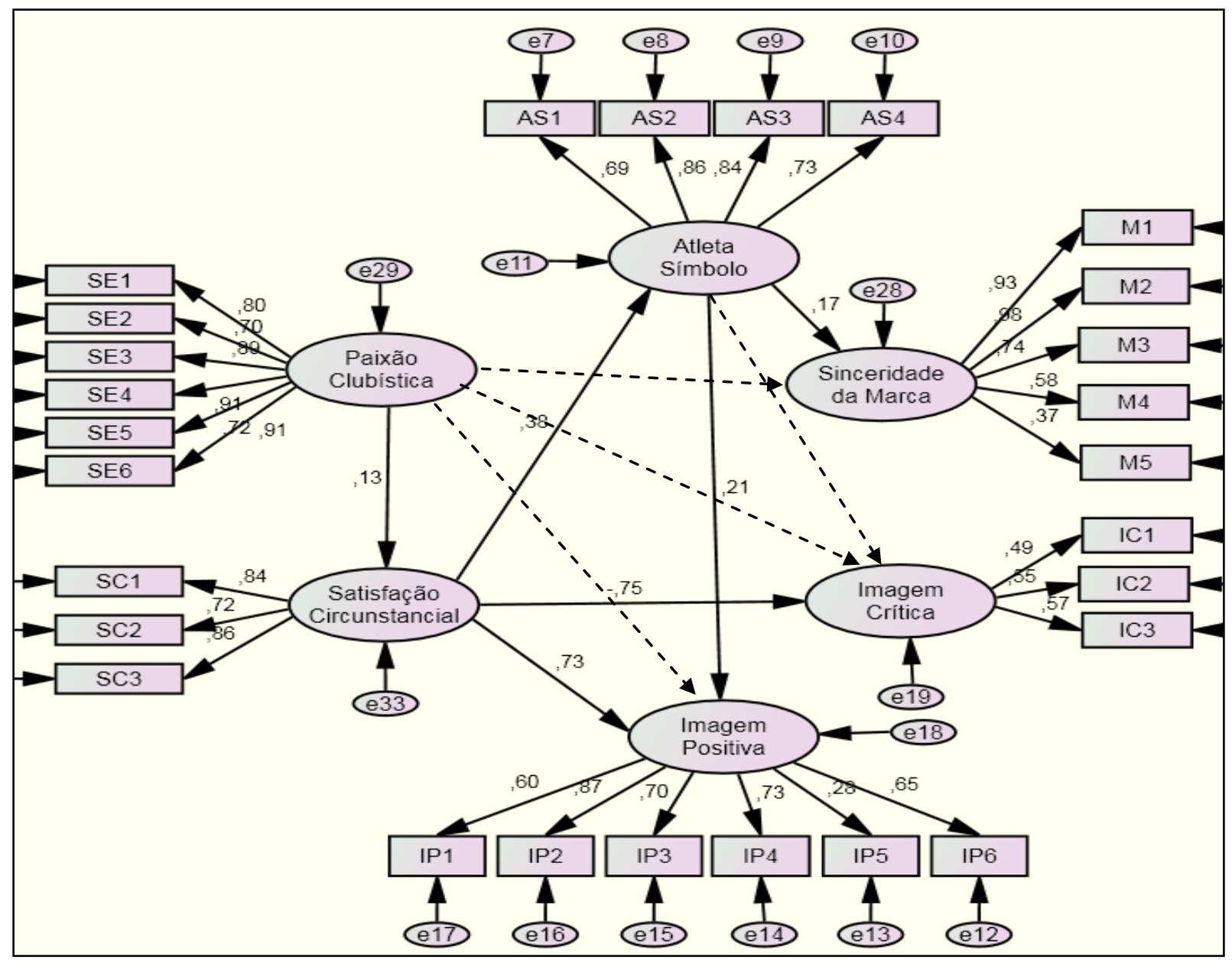


Fonte: Dados da pesquisa.

A primeira hipótese testada sugere que a paixão do torcedor pelo time do coração influencia positivamente a imagem do clube, e que esta relação seja mediada pela satisfação circunstancial, resultante do desempenho do time e da conduta dos seus dirigentes. Conforme a teoria revisada, torcedores mais apaixonados tendem a ver o time com melhores olhos do que aqueles menos envolvidos com a vida do clube. Mas a paixão pelo clube, se tomada isoladamente, não assegura a criação de uma imagem positiva na mente dos torcedores. Para a paixão converter-se em avaliação positiva (do clube, dos jogadores, dos dirigentes, etc.) no imaginário dos torcedores, é fundamental que o time corresponda às expectativas, que bons resultados acontecerem, e que a torcida tenha mais momentos de alegria do que de frustração.

Face ao exposto, era esperado que os torcedores mais satisfeitos com o desempenho da equipe e da diretoria do clube avaliassem, de forma significativamente melhor (H1a), a imagem do clube, e que o oposto acontecesse em relação aos menos satisfeitos com o desempenho recente do time (H1b).

O resultado, conforme se observa na Tabela 2 , confirma ambas as hipóteses. Ainda que a relação paixão $\rightarrow$ satisfação circunstancial tenha significância apenas periférica $(P=0,10)$, as relações seguintes não deixam dúvida de que a satisfação gerada pelo desempenho do time influencia forte e diretamente $(P<0,00)$ a construção de uma imagem positiva, e reduz significativamente $(P<0,00)$ a imagem crítica dos torcedores. Mantêm-se, assim, plenamente, as hipóteses H1a e H1b.

Tabela 2 - Relações estruturais referentes às hipóteses H1a e H1b

\begin{tabular}{|c|c|c|c|c|c|}
\hline Antecedentes & Consequentes & Estimativa & S.E. & C.R & $\mathbf{P}$ \\
\hline $\begin{array}{l}\text { Paixão } \\
\text { Clubística }\end{array}$ & $\begin{array}{c}\text { Satisfação } \\
\text { Circunstancial }\end{array}$ & 0,131 & 0,08 & 1,635 & 0,10 \\
\hline $\begin{array}{c}\text { Satisfação } \\
\text { Circunstancial }\end{array}$ & Imagem Positiva & 0,665 & 0,09 & 7,352 & *** \\
\hline Satisfação & Imagem Crítica & $-0,402$ & 0,08 & $-5,022$ & *** \\
\hline
\end{tabular}


Circunstancial

Fonte: Dados da pesquisa.

Conforme hipótese, a relação entre a paixão pelo clube e a imagem do atleta símbolo também é mediada pela satisfação circunstancial. A paixão pelo time favorece a satisfação do torcedor com relação ao momento vivido pelo clube (aumenta a satisfação durante as boas fases do time e reduz o impacto negativo nos momentos difíceis), e esta satisfação medeia a relação entre a paixão e a imagem do atleta símbolo. Significa que, quando o torcedor enxerga o clube vivenciando um bom momento (por exemplo, uma grande conquista), o atleta símbolo tende a ser visto de forma mais favorável; o contrário ocorre durante os períodos ruins. Mantêm-se, assim, as hipóteses H2a e H2b. Não foi encontrada relação direta entre a paixão clubística e o atleta símbolo da equipe. Portanto, para este ser idolatrado pelo torcedor, é condição necessária o clube estar vivendo um bom momento. As evidências destas relações estão expostas na Tabela 3.

Tabela 3 - Relações estruturais referentes às hipóteses $\mathrm{H} 2 \mathrm{a}$ e H2b

\begin{tabular}{cccccc}
\hline Antecedente & Consequente & Estimativa & S.E. & C.R & P \\
\hline Paixão Clubística & Satisfação & 0,131 & 0,08 & 1,635 & 0,10 \\
Satisfação Circunstancial & $\begin{array}{c}\text { Circunstancial } \\
\text { Atleta Símbolo }\end{array}$ & 0,238 & 0,056 & 4,21 & $* * *$ \\
\hline
\end{tabular}

Fonte: Dados da pesquisa.

A hipótese 3 deste estudo estabelecia uma relação entre o atleta símbolo e a imagem do clube, partindo do pressuposto de que, quanto melhor fosse a imagem do atleta símbolo, melhor seria a imagem do clube. Durante a fase exploratória, foram identificados dois fatores referentes à imagem clubística: um correspondente à imagem positiva do clube, com boa confiabilidade; e outro reunindo aspectos negativos da imagem (denominado de crítica do clube), cuja confiabilidade deixava a desejar.

Durante a análise confirmatória, verificou-se que a imagem do atleta símbolo influencia significativamente a imagem positiva do clube (Tabela 4); porém, não tem efeito significante na imagem crítica. Isto expressa que, quando o atleta consegue assumir um papel de destaque no time, desempenhando com louvor suas atividades, tanto o clube como 
seus dirigentes colhem os frutos dessa conduta. Mas o oposto não acontece, necessariamente, quando o atleta símbolo não corresponde às expectativas ou tem a sua imagem afetada por qualquer problema.

Tabela 4 - Relações estruturais referentes à hipótese H3

\begin{tabular}{cccccc}
\hline Antecedente & Consequente & Estimativa & S.E. & C.R. & P \\
\cline { 1 - 6 } Imagem Positiva & Atleta Símbolo & 0,313 & 0,105 & 2,979 & 0,003 \\
\hline
\end{tabular}

Fonte: Dados da pesquisa.

O pressuposto de que a imagem do clube influencia a imagem da marca patrocinadora $(\mathrm{H} 4)$ não foi confirmado. Não se verificou nenhuma relação significativa entre a imagem do clube, seja positiva ou crítica, diretamente na marca patrocinadora dos clubes de futebol. Em contrapartida, quando se trata da imagem do atleta símbolo, percebe-se que este influencia positivamente a marca por ele endossada; portanto, a hipótese 5 se mantém (Tabela 5). Este achado assume importância gerencial, pois, para os torcedores enxergarem a sinceridade da marca patrocinadora, é preciso que ela esteja associada à imagem do atleta símbolo do clube, e não apenas à instituição.

Tabela 5 - Relações estruturais referentes à hipótese H5

\begin{tabular}{ccccccc}
\hline Antecedente & Consequente & Estimativa & S.E. & C.R. & P \\
\hline Atleta Símbolo & & Sinceridade da marca & 0,266 & 0,133 & 2,002 & 0,045 \\
\hline
\end{tabular}

Fonte: Dados da pesquisa.

Após análise das hipóteses, algumas respostas científicas puderam ser observadas, as quais estão comentadas a seguir.

\section{CONSIDERAÇÕES FINAIS}

O marketing esportivo tem se mostrado uma importante ferramenta para as empresas. A vinculação da marca institucional a uma entidade esportiva, que representa paixão e diversão na vida dos espectadores, rejuvenesce a marca e ainda proporciona visibilidade alternativa à propaganda tradicional, ao passo que o esporte é considerado uma mídia capaz de proporcionar maior exposição a custos mais baixos. Logo, o patrocínio esportivo atua como estratégia diferenciada, permitindo às organizações atingirem um 
público específico, porém massificado (FERRARI; SILVEIRA, 2009). Não obstante, a utilização desta ferramenta requer a compreensão da forma como o público esportivo percebe uma marca patrocinadora. Conforme o que pode ser observado neste estudo, a ligação entre uma marca e uma entidade esportiva não ocorre diretamente. Diversas conexões e requisitos são necessários para o torcedor perceber o patrocinador e cumprir-se a finalidade do patrocínio esportivo.

O mesmo ocorre quando se trata de patrocínio a atletas, pois, para atender seu propósito, em se tratando de um contexto no qual o sentimento está inserido, a satisfação dos torcedores faz-se mediadora da forma como uma marca do patrocinador é percebida. Desta maneira, quando se trata da paixão por um clube de futebol, é possível extrair uma diversidade de informações e, para utilizar o patrocínio como uma ferramenta de marketing, é fundamental entender como ocorrem as relações entre os espectadores do esporte com o clube, com os atletas e com a marca patrocinadora. Portanto, os achados de Meenaghan (2001) são confirmados, sob a forma de se verificar uma resposta emocional do torcedor para com o patrocinador.

Este estudo busca responder como a paixão por um time de futebol influencia na forma como as pessoas percebem uma marca endossada pelo clube e por seus jogadores. Neste sentido, com base nas análises realizadas, pode-se afirmar que a percepção da marca patrocinadora de um clube de futebol é mais bem avaliada quando se associa à imagem do atleta símbolo da equipe, do que propriamente aos símbolos do clube. Assim, para as empresas que utilizam o patrocínio como forma de obter retornos financeiros e institucionais, é fundamental a imagem da marca estar, de alguma forma, vinculada à imagem do atleta símbolo, e que este efetivamente corresponda aos valores que a marca busca transmitir, pois a paixão pelo clube não se transfere diretamente para a marca patrocinadora.

O presente trabalho apresenta contribuições teóricas e gerenciais. Do ponto de vista teórico, confirma os postulados de Leocádio et al. (2007) e de Grohs e Reisinger (2014), de o patrocínio esportivo realmente poder ser benéfico e eficaz para a expansão e visibilidade da marca. Cabe ressaltar, neste contexto, as recomendações de Grohs e Reisinger (2014), ao 
destacarem a dosagem certa de patrocínio, onde a falta ou o excesso de patrocinadores pode prejudicar o evento esportivo.

Contudo, Leocádio et al. (2007) ressaltam que conhecer o perfil dos torcedores é fator essencial para a eficácia do patrocínio. Entender o público esportivo permite uma ação de patrocínio direcionada às necessidades dos torcedores. Conforme pode ser observado neste estudo, não parece ser garantia de sucesso o patrocínio direcionado somente a aspectos ligados ao clube. Esta ação pode render ainda mais quando vinculada à imagem do atleta símbolo da equipe. Keller e Machado (2006), Melo Neto (2007) e Escobar (2002) afirmam que utilização de um atleta bem sucedido é uma ótima estratégia para as empresas, vistos a dedicação e o sucesso do jogador adicionarem valor à marca do patrocinador.

Do ponto de vista gerencial, o trabalho poderá ser bastante útil aos dirigentes esportivos no momento de negociar patrocínio para suas equipes, e aos profissionais de marketing em geral, nas decisões envolvendo o mix de comunicação, a escolha de mídias, quotas de patrocínio e outras. Algumas questões, como aquelas abrangendo o valor dos espaços para divulgação de anúncios nos estádios, nos uniformes e nos adereços utilizados pelos atletas, podem ser largamente beneficiadas pelos resultados aqui apresentados, tendo em vista a importância que assume o endosso pessoal do atleta símbolo na relação entre o torcedor e a marca.

A constatação de a imagem do atleta símbolo influir significativamente na modelagem da imagem do clube como um todo (incluindo a dos diretores), reforça a necessidade de os dirigentes investirem na contratação de jogadores que se destaquem também pelo caráter e não apenas pela técnica. O mesmo ocorre em relação à marca patrocinadora, cuja exposição, mesmo que menor, poderá ser mais vantajosa quando exibida pelo atleta símbolo (ex.: na entrevista ao final da partida), do que quando exibida em grandes painéis dentro do estádio.

A principal limitação do estudo foi o fato de a amostra ter ocorrido por conveniência. É sempre mais indicado que a amostra seja aleatória, ou fato limitante a ser observado foi o objetivo de estudo, sendo que os resultados encontrados limitam-se aos clubes analisados, não necessariamente extrapolados aos demais. 
Portanto, encoraja-se a realização de novos trabalhos do mesmo gênero, a fim de verificar se os resultados aqui encontrados replicam-se em outras regiões e a outros clubes. Recomenda-se, ainda, uma análise mais ampla contendo um número maior de torcedores e, até mesmo, de mais clubes.

\section{REFERÊNCIAS}

AAKER, J. L. Dimensions of Brand Personality. Journal of Marketing Research, v. 34, n. 3, 1997.

ARAI, Akiko; KO, Yong Jae; ROSS, Stephen. Branding athletes: Exploration and conceptualization of athlete brand image. Sport Management Review, v. 17, n. 2, p. 97-106, 2014.

BAUER, H. H.; SAUER, N. E.; EXLER, S. Brand Image and Fan Loyalty in Professional Team Sport: A Refined Model and Empirical Assessment. Journal of Sports Management, v. 22, 2008.

BELK, R. W. Possessions and the Extended Self. The Journal of Consumer Research, v. 15, n. 2, 1988.

BORGES, G. R.; AÑAÑA, E. S. A Relação Entre a Imagem da Marca e a Lealdade dos Torcedores de Clubes de Futebol. In: ENCONTRO DE MARKETING DA ANPAD, 4, 2010, Florianópolis. Anais... Florianópolis: AMA, 2010.

BRANCHI, N. V. L. O Patrocínio Esportivo no Composto Comunicação das Empresas. 2002. 138f. Tese (Mestrado em Administração) - Escola de Administração, Universidade Federal do Rio Grande do Sul, Porto Alegre.

BUDOLLA, M. S.; EMMERICK, A.; FREGA, J. R.; SANTOS, C. B. Influência, reconhecimento e lembrança de marcas: o patrocínio esportivo da Categoria Stock Car na Região Metropolitana de Curitiba. In: CONGRESSO INTERNACIONAL DE COMUNICAÇÃO E MARKETING, 3., 2006, Curitiba. Anais... Curitiba, 2006.

BUDOLLA, M. S.; SOUZA, A. O Patrocínio Esportivo como Canal de Comunicação da Estratégia Mercadológica: o Estudo de Caso do Banco do Brasil. In: ENCONTRO ANUAL DA ANPAD, 29., 2005, Brasília. Anais..., Brasília: ENANPAD, 2005.

CARVALHO, I. M. de; VERAS, V. M. A propriedade intelectual como elemento estratégico da gestão do conhecimento. Revista Eletrônica de Estratégia \& Negócios, v. 1, n. 2, p. p. 43-68, 2010.

DAS, G. Impacts of retail brand personality and self-congruity on store loyalty: the moderating role of gender. Journal of Retailing and Consumer services, v. 21, n. 2, p. 130138, 2014. 
EKINCI, Y.; HOSANY, S. Destination Personality: an application of Brand Personality to tourism destinations. Journal of Travel Research, v. 45, 2006.

ERDOGAN, B. Z. Celebrity Endorsement: a literature review. Journal of Marketing Management, v. 15, 1999.

ESCOBAR, M. N. Patrocínio Esportivo e seus Efeitos sobre o Valor da marca: um estudo exploratório no Brasil. 2002. 210f. Tese (Mestrado em Administração de Empresas) - Escola de Administração de Empresas, Fundação Getúlio Vargas, São Paulo.

FERRARI, T. D.; SILVEIRA, R. B. Pra qual time você torce? O Marketing e as Estratégias de Patrocínio Esportivo. In: SEMINÁRIOS EM ADMINISTRAÇÃO: EMPREENDEDORISMO E INOVAÇÃO, 20., 2009, São Paulo. Anais..., São Paulo: SEMEAD, 2009.

FUNK, Daniel. Consumer behaviour in sport and events. Routledge, 2008.

GASPAR, Marcos Antonio et al. Relacionamentos interorganizacionais: fatores influencidores, facilitadores e dificultadores na formação de rede de cooperação. Revista Eletrônica de Estratégia \& Negócios, v. 7, n. 1, p. 213-241, 2014.

GIGLIO, E. A. M. O Impacto da credibilidade do endossante sobre a reação dos consumidores em relação às propagandas: um estudo de caso. In: CONGRESSO BRASILEIRO DE CIÊNCIAS DA COMUNICAÇÃO, 37., 2004, Porto Alegre. Anais..., Porto Alegre: Intercom, 2004.

GIGLIO, E. M. O Comportamento do Consumidor. São Paulo: Cengage Learning, 2010.

GROHS, R.; REISINGER, H. Sponsorship effects on brand image: The role of exposure and activity involvement. Journal of Business Research, v. 67, n. 5, p. 1018-1025, 2014.

HAIACHI, M. de C.; MATARUNA, L. Patrocínio no esporte: uma visão das melhores empresas sobre a escolha de modalidades esportivas como forma de investimento. Revista Digital Buenos Aires, ano 13, n. 119, 2008. Disponível em:

<http://www.efdeportes.com/efd119/patrocinio-no-esporte.htm>. Acesso em: 09 ago. 2011.

HAIR, JR., J. F.; ANDERSON, R. E.; TATHAM, R. L.;BLACK, W. C. Análise Multivariada de Dados. Porto Alegre: Bookman, 2005.

HOYE, R.; SMITH, A.; WESTERBEEK, H.; STEWART, B; NICHOLSON, M. Sport Management: Principles and Applications. Burlington: Elsevier, 2006.

KELLER, L. K.; Brand Synthesis: the Multidimensionality of Brand Knowledge. Journal of Consumer Research, v. 29, 2003.

KELLER, L. K.; MACHADO, M. Gestão Estratégica de Marcas. São Paulo: Pearson Prentice Hall, 2006.

KOTLER, P.; KELLER, K. L. Administração de Marketing. São Paulo: Pearson Prentice Hall, 2006. 
LEOCÁDIO, A. L.; SILVESTRE, A. C. D.; PORTELA, D. Z.; NAKAJIMA, L. Y.; SILVA, T. F. da. Marketing esportivo no campeonato brasileiro de futebol: relação entre empresas investidoras e times patrocinados. In: SEMINÁRIOS EM ADMINISTRAÇÃO, 10., 2007, São Paulo. Anais..., São Paulo: SEMEAD, 2007.

MALHOTRA, N.K. Pesquisa de Marketing: uma orientação aplicada. Porto Alegre: Bookman, 2001.

MATTAR, M. F. Tomada de decisão em ações de patrocínio esportivo: análise descritiva do processo decisório e critérios de seleção em empresas patrocinadoras no Brasil. 2007. 160f. Tese (Mestrado em Administração) - Departamento de Administração, Universidade de São Paulo, São Paulo.

MAYER, M. M. Futebol: O Negócio por Trás do Jogo - Estudo de Caso do São Paulo Futebol Clube. 2010. 89f. Tese (Mestrado em Gestão Empresarial) - Escola Brasileira de Administração Pública e de Empresas, Fundação Getúlio Vargas, Rio de Janeiro, 2010.

MEENAGHAN, Tony. Understanding sponsorship effects. Psychology \& Marketing, v. 18, n. 2, p. 95-122, 2001.

MELO NETO, F. P. de. Marketing esportivo. Rio de Janeiro: Record, 2007.

MISHRA, P.; DHAR, U.; RAOTIWALA, S. Celebrity Endorsers and Adolescents: A Study of Gender Influences. Vikalpa, v. 26, n. 4, 2001.

MOZOTA, Brigitte Borja de. Design management: using design to build brand value and corporate innovation. Skyhorse Publishing Inc., 2003.

MUNIZ, K. M. Avaliação das Dimensões da Personalidade de Marca no Contexto Brasileiro. 2005. 201f. Tese (Mestrado em Administração) - Centro de Ciências Sociais Aplicadas, Pontifícia Universidade Católica do Paraná, Curitiba, 2005.

OHANIAN, R. Onstruction and Validation of a Scale to Measure Celebrity Endorsers' Perceived Expertise, Trustworthiness and Attractiveness. Journal of Advertising, v. 19, n. 3, 1990.

OLIVEIRA, Rezilda Rodrigues. Enfoques multitemáticos para a gestão de organizações não governamentais. Revista Eletrônica de Estratégia \& Negócios, v. 3, n. 1, p. p. 144-167, 2010.

OLIVER, R. L. Whence Consumer Loyalty? Journal of Marketing, v. 63, 1999.

PARMENTIER, M.-A.; FISCHER, E. How athletes build their brands. International Journal of Sport Management and Marketing, v. 11, n. 1, p. 106-124, 2012.

REIS, H. H. B. Paixão e violência no futebol. Pré-Univesp. Revista Digital de Apoio Universitário. 2010. Disponível em: <http://www.univesp.ensinosuperior.sp.gov.br/ preunivesp/118/paix-o-e-viol-ncia-no-futebol.html> Acesso em: 18 set. 2011. 
SCHLESINGER, Walesska et al. Patrocinio deportivo: la implicación del espectador y sus efectos en la identificación y lealtad. Cuadernos de Gestión, v. 12, n. 2, p. 59-76, 2012.

SCOTT, L. M. The Troupe: Celebrities as Dramatis Personae in Advertisements. Advances in Consumer Research, v. 18, 1991.

SOUZA, R. V.; HENRIQUE, J. L.;BREI, V. A. Avaliação da Relação entre Self Estendido, Fluxo, Vínculo e Satisfação em Ambientes Virtuais. In: ENCONTRO DA ANPAD, 30, 2006, Salvador. Anais... Salvador: EnANPAD, 2006.

ZIKMUND, W. G. Princípios da Pesquisa de Marketing. São Paulo: Pioneira Thomson Learning, 2006.

ZUNINO, R. Comportamento de Compra de Torcedores de Clubes de Futebol: Um Estudo da Aquisição de Produtos dos Patrocinadores. In: ENCONTRO DE MARKETING DA ANPAD, 2, 2006, Rio de Janeiro. Anais... Rio de Janeiro: EMA, 2006. 